Jurnal Riset Agama

Volume 1, Nomor 2 (Agustus 2021): 449-457

DOI: $10.15575 /$ jra.v1i2.14762

https://journal.uinsgd.ac.id/index.php/jra

\title{
Keutamaan Memelihara Kucing dalam Perspektif Islam: Studi Takhrij dan Syarah Hadits
}

\author{
M. Faizhil Akbar \\ Jurusan Ilmu Al-Qur'an dan Tafsir, Fakultas Ushuluddin \\ UIN Sunan Gunung Djati Bandung \\ faizhilakbar04@gmail.com
}

\begin{abstract}
This study has the aim of discussing the hadith about the dangers of keeping a cat by not caring for it properly or mistreating it such as locking it up by not giving it food and water. This study uses a qualitative method through a literature study applying the takhrij and syarah hadith methods through contemporary analysis. The result of this research is that the quality of the hadith about the dangers of keeping a cat by molesting it is found to be authentic according to the consensus of scholars and the results of a research review. With the rise of the cat lover community today, it is very helpful in increasing awareness of cats as well as providing education to the public. As we know cats are the favorite pets of the Prophet Muhammad SAW, because cats are not only cute, they are also clean and free from unclean animals, in Islam it is legal to keep a cat. Of the several virtues of keeping a cat, one of them is an activity that is favored by Allah SWT. There are conclusions that can be drawn from this research, namely increasing our concern for cats in maintaining them and freeing them from hunger or thirst, which are found in our environment.
\end{abstract}

Keywords: Cat; Hadith; Maintain.

\begin{abstract}
Abstrak
Studi ini memeliki tujuan yaitu membahas hadis tentang bahaya memelihara kucing dengan tidak memeliharanya dengan baik atau menganiayanya seperti mengurungnya dengan tidak memberikan makan dan minum. Studi ini menggunakan metode kualitatif melalui studi pustaka mengaplikasikan metode takhrij dan syarah hadis melalui analisis kontemporer. Buah dari riset ini adalah ditemukan kualitas hadis tentang bahaya memelihara kucing dengan menganiayanya yaitu berstatus shahih menurut ijma' ulama dan hasil tinjauan penelitian. Dengan maraknya komunitas pecinta
\end{abstract}


Jurnal Riset Agama, Volume 1, Nomor 2 (Agustus 2021): 449-457

M. Faizhil Akbar/Keutamaan Memelihara Kucing dalam Perspektif Islam: Studi Takhrij dan Syarah Hadits

kucing saat ini, sangat membantu dalam peningkatan kepedulian terhadap kucing sekaligus mereka juga memberikan edukasi kepada masyarakat. Sebagaimana yang kita ketahui kucing adalah hewan peliharaan kesayangan Nabi Muhammad SAW, sebab kucing selain lucu mereka juaga hewan yang bersih dan bebas dari najis, dalam Islam hukum memelihara kucing yaitu boleh. Dari beberapa keutamaan memelihara kucing salah satunya yaitu kegiatan yang disukai oleh Allah SWT. Terdapat kesimpulan yang bisa diambil dari riset ini yaitu meningkatkan kepedulian kita terhadap kucing dalam memeliharanya maupun membebaskannya dari kelaparan atau kehausan, yang dijumpai di sekitar lingkungan kita.

Kata kunci: Hadis; Kucing; Memelihara.

\section{Pendahuluan}

Kucing adalah hewan kesayangan Nabi Muhammad SAW yang dikenal dalam agama Islam. Bahkan belakangan ini kucing banyak orang yang ingin memeliharanya. Tidak sedikit orang yang menyukainya. Kucing adalah binatang yang jauh dari najis dan selalu ada di sekitar manusia (Adil Sa'di, 2008). Sebagaimana yang tertera pada hadis: "Kucing tidak najis. Ia binatang yang ada di sekitar kalian" (HR. Abu Dauwud dan Tirmidzi). Islam telah mendudukkan hukum memelihara kucing. Hukum tersebut membahas tentang keutamaan memelihara kucing hingga hukum bagi orang yang menyiksanya.

Dalam Islam hukum memelihara kucing yaitu boleh (Krishandini, 2021). Nabi Muhammad juga berpesan untuk menyayangi kucing peliharaan layaknya keluarga sendiri. Kucing sudah dikenal sejak zaman kerajaan kuno, sebagai binatang yang selalu setia bersama raja dan ratu. Kucing disebut hewan kesayangan di dalam agama Islam. Ia dapat memberikan kebahagiaan bagi manusia. Kucing juga dapat mereda amarah dan stress pada manusia. Ia binatang peliharaan yang lucu, jinak, dan besih. Ada sebuah hadis yang mejelaskan bahwa kucing lebih bersih dari manusia dan liurnya bersifat membersihkan.

Memelihara kucing dalam Islam bukanlah perbuatan sia-sia atau tidak ada artinya. Rasulullah SAW bersabda bahwa memelihara hewan dengan baik maka akan mendapat pahala. Sejak zaman dahulu, kucing telah dihormati di Timur Tengah tradisi yang diadopsi oleh Islam, walaupun sudah banyak perubahan (Baldick, 2012).

Dahulu ada seorang penyair dan juga sekaligus penulis wisata yang berasal dari Amerika Serikat yaitu Bayard Taylor (1825-1878) ia terkejut 
Jurnal Riset Agama, Volume 1, Nomor 2 (Agustus 2021): 449-457

M. Faizhil Akbar/Keutamaan Memelihara Kucing dalam Perspektif Islam: Studi Takhrij dan Syarah Hadits

ketika melihat sebuah rumah sakit di Suriah yang mana ditemukan banyak kucing berkeliaran di sana. Kucing domestik tersebut dilindungi dan dipelihara oleh sebuah lembaga yang mana didanai dari wakaf, termasuk upah pengasuh, perawatan dan makanan kucing. Edward William Lane (1801-1876), bersal dari Britania Raya ia seorang orientalis yang menetap di Kairo. Ia menjelaskan bahwa terdapat taman kucing pemberian dari sultan Mesir yang bernama Baibars, pada masa itu yaitu seratus tahun ke-13 yang mana di Eropa pada waktu itu banyaknya orang menyikapi kucing dengan tidak lazim yaitu seperti memakannya ataupun membunuhnya dan itu semua melalui keputusan paus(Campo, 2009).

Beberapa penelitian telah melakukan pembahasan seputar hal ini. Antara lain Siti Mira (2017), “Komunitas Kucing dengan Fenomena Gaya Hidup di Bandung," Universitas Pasundan. Metode yang digunakan yaitu kualitatif yang mana di dalam penelitiannya ia mengunakan teori Fenomenologi dari Alfred Schutz. Buah dari penelitiannya yaitu tidak sebatas memelihara kucing saja, akan tetapi juga ada edukasi yang dilakukan oleh komunitas pecinta kucing. Komunitas ini didirikan bertujuan sebagi wadah untuk mempersatukan para penyuka kucing. Bersosialisasi kepada masyarakat juga sering dilakukan oleh komunitas ini, seperti cara-cara yag tepat untuk merawat kucing, pergi ke panti asuhan untuk memberikan bantuan dan berpartisipasi dalam kegiatankegiatan tentang kucing (R.M. Siti, 2017). Citra Ayu Indah Permata Sari (2016), “Komunitas Konsumen Penyayang Kucing dengan Sosiolinguistik Komunikasi: Observasi terhadap Komunitas Pecinta Kucing Jakarta (KPKJ)," Ilmu Komunikasi Universitas Bakrie. Metode yang digunakan kualitatif, yang mana dilakukan dengan teknik observasi dan mengumpulkan data, mewawancarai secara lebih dalam dan menelusuri objek. Buah dari penelitian ini yaitu mejelaskan makna kucing dan beberapa istilah yang sering dipakai, inilah segelintir fenomena komunikasi yang terdapat di KPKJ (C.A.I Permatasari, 2016). Diana Savitri dan Rizqi Khoirunnisa (2014), "Pemilik Hewan Peliharaan yang Hidup Jauh dari Keluarga dengan Kesepian yang Dialaminya," Universitas Muhammadiyah Malang. Penelitian ini bertujuan untuk meninjau seberapa kesepian mahasiswa yang memelihara hewan yang mana hidup terpisah dari keluarganya. Kuantitatif deskriptif merupakan metode yang dipakai serta revisi dari Universitas California. Penelitian ini memiliki hasil yaitu menggambarkan kesepian yang dialami pada tingkat rendah ada 36 penderita sedangkan kesepian yang dialami pada tingkat cukup tinggi ada 14 penderita (Rizqi Khoirunnisa Nurlayli, 2014).

Berbeda antara beberapa studi yang telah terpapar di atas dengan penelitian ini yaitu penulis akan membahas tentang keutamaan memelihara kucing melalui takhrij hadis, yang mana hadis yang digunakan di sini yaitu yang diriwayatkan oleh Imam Bukhari No. 3482 
Jurnal Riset Agama, Volume 1, Nomor 2 (Agustus 2021): 449-457

M. Faizhil Akbar/Keutamaan Memelihara Kucing dalam Perspektif Islam: Studi Takhrij dan Syarah Hadits

versi syarah shahih Bukhari, setelah mengetahui status hadis kemudian dilakukan syarah untuk menjelaskan makna yang terkandung dalam teks hadis, bunyi hadis tersebut yaitu "seorang wanita yang menganiaya seekor kucing mengurungnya dengan tidak memberi makan dan minum hingga kucing tersebut kelaparan, dan tidak melepaskannya agar dapat mencari makan di luar dan menyebabkan wanita itu disiksa." Dari matan hadis tersebut, dapat diambil pelajaran bahwa dalam memelihara kucing janganlah sampai kita menganiayanya disebabkan tidak memberinya makan ataupun minum, hal tersebut sama saja dengan tindakan aniaya atau menyiksa. Oleh karena itu, sebaiknya dalam memelihara kucing seharusnya kita benar-benar memperhatikan kebutuhannya, seperti makan, minum, dan perawatan lainnya.

Setelah melakukan uraian di atas, maka langkah selanjutnya adalah menyusun formula penelitian, yaitu rumusan masalah, pertanyaan utama studi dan tujuan studi (Darmalaksana, 2020a). Rumusan masalah penelitian ini adalah terdapat syarah hadis tentang keutamaan memelihara kucing. Pertanyaan utama penelitian ini adalah bagaimana syarah hadis tentang keutamaan memelihara kucing. Sedangkan pertanyaan terperinci sebagai berikut: 1) Bagaimana teks hadis tentang keutamaan memelihara kucing; 2) Bagaimana kualitas hadis tentang keutamaan memelihara kucing; dan 3) Bagaimana syarah hadis tentang keutamaan memelihara kucing. Tujuan penelitian ini yaitu membahas syarah hadis tentang keutamaan memelihara kucinng.

\section{Metode Penelitian}

Penelitian ini menggunakan metode pendekatan kualitatif melalui studi pustaka dengan menerapkan metode takhrij hadis dan syarah hadis. Adapun interpetasi digunakan analisis isu kontemporer (Darmalaksana, 2020b).

\section{Hasil Penelitian dan Pembahasan}

Hasil penelitian dan pembahasan di bawah ini.

\section{Teks Hadis}

Berdasarkan penelusuran hadis pada aplikasi Ensklopedia Hadis Kitab 9 Imam, dengan menggunakan kata kunci "Kucing" maka, ditemukan beberapa hadis yang terkait dengan memelihara kucing, namun, dalam pembahasan ini hanya satu hadis yang dipakai dalam riset ini yaitu hadis riwayat al-Bukhari No. 3482 versi Fathul Bari Kitab hadis tentang para Nabi bab gua, sebagi berikut:

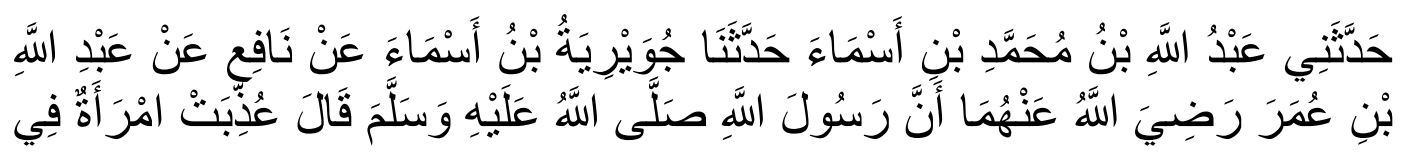


Jurnal Riset Agama, Volume 1, Nomor 2 (Agustus 2021): 449-457

M. Faizhil Akbar/Keutamaan Memelihara Kucing dalam Perspektif Islam: Studi

Takhrij dan Syarah Hadits

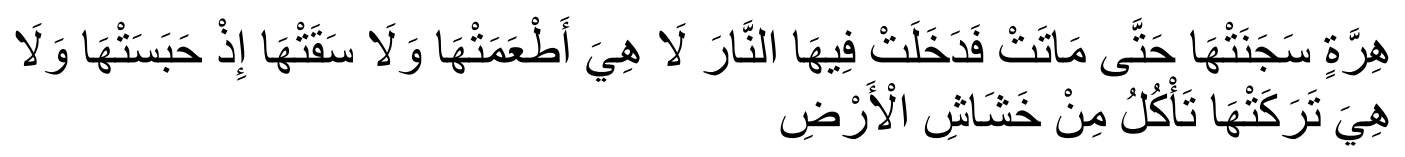

Artinya: Telah bercerita kepadaku 'Abdullah bin Muhammad bin Asma' telah bercerita kepada kami Juwairiyah bin Asmai dari Nafi' dari 'Abdullah bin 'Umar radhiallahu'anhuma bahwa Rasulullah bersabda, "Ada seorang wanita disiksa disebabkan seekor kucing yang dikurungnya hingga mati kelaparan lalu wanita itupun masuk neraka karena dia tidak memberinya makan dan minum ketika mengurungnya, dan tidak melepaskannya sehingga dia dapat menyantap serangga tanah" (Saltanera, 2015).

\section{Daftar Rawi dan Sanad}

Takhrij hadis memelihara kucing tersusun dalam bentuk tabel sebagai berikut:

Tabel 1. Daftar Rawi dan Sanad

\begin{tabular}{|c|c|c|c|c|c|c|}
\hline \multirow[t]{2}{*}{ No. } & \multirow{2}{*}{$\begin{array}{l}\text { Rawi } \\
\text { Sanad }\end{array}$} & Lahir/ Wafat & \multirow{2}{*}{ Negeri } & \multirow{2}{*}{ Kuniyah } & Komentar Ulama & \multirow{2}{*}{ Kalangan } \\
\hline & & $\mathbf{W}$ & & & + & \\
\hline 1 & $\begin{array}{l}\text { Abdullah bin } \\
\text { ‘Umar bin } \\
\text { Khaththab bin } \\
\text { Nufail }\end{array}$ & $73 \mathrm{H}$ & Madinah & $\begin{array}{l}\text { Abu } \\
\text { 'Abdur } \\
\text { Rahman }\end{array}$ & $\begin{array}{l}\text { Ibnu Hajar } \\
\text { al-Atsqalani: } \\
\text { Shahabat; } \\
\text { Adz- } \\
\text { Dzahabi: } \\
\text { Shahabat; }\end{array}$ & Shahabat \\
\hline 2 & $\begin{array}{l}\text { Nafi', maula } \\
\text { Ibnu 'Umar }\end{array}$ & $117 \mathrm{H}$ & Madinah & $\begin{array}{l}\text { Abu } \\
\text { 'Abdullah }\end{array}$ & $\begin{array}{l}\text { Yahya bin } \\
\text { Ma'in: } \\
\text { Tsiqah; } \\
\text { Al-'Ajli: } \\
\text { Tsiqah; } \\
\text { An-Nasa'i: } \\
\text { Tsiqah; } \\
\text { Ibnu } \\
\text { Kharasy: } \\
\text { Tsiqah }\end{array}$ & $\begin{array}{l}\text { Tabi'in } \\
\text { kalangan } \\
\text { biasa }\end{array}$ \\
\hline 3 & $\begin{array}{l}\text { Juwairiyah bin } \\
\text { Asma' bin } \\
\text { ‘Ubaid }\end{array}$ & $173 \mathrm{H}$ & Bashrah & $\begin{array}{l}\text { Abu } \\
\text { Mukhariq }\end{array}$ & $\begin{array}{l}\text { Abu Hatim: } \\
\text { Shalih; } \\
\text { Ibnu Hibban: } \\
\text { disebutkan } \\
\text { dalam 'ats- } \\
\text { tsiqaat; } \\
\text { Ibnu Hajar } \\
\text { al-'Asqalani: } \\
\text { Shaduuq; } \\
\text { Adz- } \\
\text { Dzahabi: } \\
\text { Tsiqah }\end{array}$ & $\begin{array}{l}\text { Tabi'ut } \\
\text { Tabi'in } \\
\text { kalangan } \\
\text { tua }\end{array}$ \\
\hline 4 & $\begin{array}{l}\text { Abdullah bin } \\
\text { Muhammad bin }\end{array}$ & $231 \mathrm{H}$ & Bashrah & $\begin{array}{l}\text { Abu } \\
\text { 'Abdur }\end{array}$ & $\begin{array}{l}\text { Abu Zu'rah: } \\
\text { la ba'sa bih; }\end{array}$ & $\begin{array}{l}\text { Tabi'ul } \\
\text { Atba' }\end{array}$ \\
\hline
\end{tabular}


Jurnal Riset Agama, Volume 1, Nomor 2 (Agustus 2021): 449-457

M. Faizhil Akbar/Keutamaan Memelihara Kucing dalam Perspektif Islam: Studi Takhrij dan Syarah Hadits

$\begin{array}{lll}\text { Asma' bin 'Abdi } & \text { Rahman } & \begin{array}{l}\text { Abu Zu'rah: } \\ \text { syaikh } \\ \text { shalih; }\end{array} \text { tualangan } \\ \text { Ibnu Hibban: } \\ \text { disebtkan } \\ \text { dalam 'ats- } \\ \text { tsiqaat; } \\ \text { Ibnu Hajar: } \\ \text { tsiqah jalil }\end{array}$

Tabel di atas merupakan daftar rawi dan sanad hadis yang diriwayatkan oleh Imam Bukhari No. 3482 versi Fathul Bari kitab hadis tentang para Nabi bab gua. Pada tabel di atas terdapat urutan rawi sanad, lahir wafat, negeri asalnya, kuniyah (panggilan), komentar para ulama, dan berasal dari kalangan mana. Hadis ini diriwayatkan oleh lima orang rawi saja, mulai dari mukharrij hingga mudawwin. Penulis tidak menemukan tahun lahirnya, hanya tahun wafatnya saja. Dilihat pada komentar ulama rata-rata positif yaitu banyak yang menyebutkan tsiqah, hanya saja ada satu komentar yang nilainya 50/50 yaitu Juwairiyah bin Asma' bin 'Ubaid yang dikomentari oleh Ibnu Hajar al-Atsqalani menyebutkan shaaduq. Akan tetapi, shaaduq termasuk kepada peringkat ta'dil al-Dzahabi dalam Mizan al-I'tidal dalam pemikirannya (Srifariyati, 2020).

\section{Kualitas Hadis}

Hadis bisa dikatakan shahih apabila adil dan dhabit rawinya, bersambung sanadnya, tidak memiliki cacat pada matan atau kesalahan dalam redaksi hadis tersebut. Ditinjau dari keempat rawi di atas berlandaskan pada komentar ulama yang mayoritas positif meskipun ada yang menyebutkan shaaduq, la ba'sa bih, dan shalih, dalam pemikirannya alDzahabi dalam Mizan al-I'tidal itu juga termasuk pada peringkat $t a^{\prime} d i l$. Seperti komentar dari Abu Hatim mengatakan Shalih; Ibnu Hajar al'Asqalani mengatakan Shaduuq; Abu Zu'rah: la ba'sa bih; Abu Zu'rah: syaikh shalih. Berikutnya dilihat dari negeri asal rawi satu dan dua sama yaitu Madinah ada kemungkinan mereka bertemu, begitu pula dengan asal rawi ketiga dan keempat juga sama yaitu di Bashrah. Dilihat dari tahun wafatnya berjarak pada kisaran 30-60 tahun. Di dalam matan tidak boleh adanya syadz dan 'illat. Menurut Muhammad Mahfudz hadis Syadz adalah hadis tersebut diriwaytkan oleh orang yang tsiqah yang tidak serupa sanad ataupun pada matannya. Disebabkan terdapat penambahan 
Jurnal Riset Agama, Volume 1, Nomor 2 (Agustus 2021): 449-457

M. Faizhil Akbar/Keutamaan Memelihara Kucing dalam Perspektif Islam: Studi Takhrij dan Syarah Hadits

ataupun pengurangan, pada riwayat dengan derjat yang lebih tinggi dilihat dari pentarjihannya. Sedangkan 'illat adalah adanya sebab masuk secara sembunyi pada hadis meyebabkan rusaknya keshahihan sehingga hadis tersebut menjadi hadis $M u^{\prime}$ allal. Ulama hadis mengartikan bahwa 'illat ini sebagai "penyakit" yang dapat merusak keshahihan hadis. Pada dasarnya, matan yang memiliki 'illat menimbulkan kecurigaan bahwa di dalam matan tersebut terdapat kesalahan. Maka dari pada itu, kecurigaan adanya kesalahan itulah yang dinamakan 'illat (Khaq, 2015). Sebagaimana yang telah ditinjau di dalam aplikasi kitab 9 Imam tertera bahwa kualitas hadis Imam al-Bukhari No. 3482 ini berstatus shahih menurut ijma' ulama (Saltanera, 2015).

\section{Syarah Hadis}

Berbicara tentang syarah hadis yaitu merupakan penjelasan keshahihan dan kecacatan pada sanad maupun matan hadis, serta menjelaskan makna-makna yang terkandung dan juga mengeluarkan hukum ataupun hikmahnya (Mukhtar, 2018). Sebagaimana isi dari hadis riwayat dari Imam al-Bukhari No. 3482 terdapat sebuah kisah seorang perempuan yang memelihara seekor kucing. Ia tidak merawat kucing tersebut dengan baik, membiarkannya tertawan sampai kucing tersebut tidak dapat melakukan apapun sehingga terlunta-lunta di dalam kandangnya. Terlebih lagi, si perempuan ini tidak memberinya makan minum. Kucing tersebut tersiksa dengan rasa haus dan lapar. Ia tidak dapat mencari makanannya sendiri sebab dikurung. Sungguh malang nasib kucing tersebut. Fitrah rasa kasih sayang mestinya ada pada perempuan akan tetapi, sifat tersebut tidak ditemukan padanya. Karena berbuat zalim terhadap binatang, perempuan ini ditimpakan oleh Allah Swt siksa. Dari kisah ini, dapat diambil hikmahnya bahwa jika memelihara binatang, agar dirawat dengan baik dan tidak menzalimi atau mentelantarkannya (Muhammad Nasrullah, 2020). Dikatakan oleh Ibnu al-Manayyar menjelaskan bahwa haram membunuh hewan yang tidak diperintahkan, apalagi membunuhnya dengan tidak memberinya minum hingga kehausan, walapun memberikan kucing minum tidak mendapat pahala, akan tetapi menyelamatkannya dari kehausan adalah sebuah kebaikan (Ibnu Hajar al-Asqalani, 2010).

Imam Nawawi rahimahullah mengatakan bahwa hadis ini mejelaskan bahwa haram hukumnya membunuh kucing dan mengurungnya dengan tidak memberi makan dan minum. Adapun maksud dari dimasukkannya kedalam neraka, itu disebabkan oleh perbuatannya. Dilihat dari zahir hadis, perempuan ini beragama Islam, meskipun begitu, yang menyebabkannya masuk neraka yaitu menyiksa seekor kucing (Abu Muslih Ari Wahyudi, 2014). Berbicara tentang keutamaan memelihara kucing, Rasulullah sangat menyayangi kucing 
Jurnal Riset Agama, Volume 1, Nomor 2 (Agustus 2021): 449-457

M. Faizhil Akbar/Keutamaan Memelihara Kucing dalam Perspektif Islam: Studi

Takhrij dan Syarah Hadits

serta memuliakannya, di lain hadis terdapat yaitu kucing yang minum di suatu wadah dan menyisakan air itu juga diperbolehkan untuk air wudhu. Memelihara kucing juga bisa mendapatkan pahala antara lain: Menjadi timbangan kebaikan; Sikap empati dilatih; Pada hari kiamat rahmat didapatkan; Ridha dan ampunan Allah Swt didapatkan; Merupakan sedekah; Diampuni dosanya; Kuman pada kucing terbilang sedikit; Hewan yang bebas dari najis; kucing suka memakan tikus atau serangga sehingga pemiliknya dapat terlindungi; Allah Swt menyukai kegiatan ini; Pahala beserta surga didapatkan; Suci air liurnya atau tidak najis; dan Disayangi penghuni langit (Dalamislam, 2021).

\section{Kesimpulan}

Buah dari riset ini adalah ditemukan kualitas hadis tentang bahaya memelihara kucing dengan menganiayanya yaitu berstatus shahih menurut ijma' ulama dan hasil tinjauan penelitian. Kucing adalah hewan kesayangan Nabi Muhammad SAW yang dikenal dalam agama Islam. Dalam Islam hukum memelihara kucing yaitu boleh. Memelihara kucing dalam Islam bukanlah perbuatan sia-sia atau tidak ada artinya. Dalam penelitian ini penulis berharap agar semua orang lebih peduli terhadap sesama makhluk hidup, karena manusia tidak akan lepas dari hubungannya dengan hewan maupun tumbuhan. Dengan adanya komunitas pecinta kucing juga dapat membantu dalam meningkatkan kepedulian manusia terhadap kucing. Apalagi kucing domestik, yang hidupnya bergantung pada sisa-sisa makanan manusia. Dalam memeliharanya jangan sekali-kali menyiksanya, dalam arti lain, mengurungnya dengan tidak memberikan makan dan minum kepadanya. Karena itu termasuk perbuatan dzalim. Adapun keutamaan yang didapatkan dalam memelihara kucing yaitu menjadi timbangan amal kebaikan bagi pemeliharanya, menjalin kasih sayang terhadap sesama makhluk, kucing ialah hewan yang terbilang cukup bersih sehingga dapat kita jadikan motivasi untuk bersih dalam hidup, memelihara kucing juga dapat diampuninya dosa, dan semoga dalam memeliharanya kucing juga dapat sebagai penolong saat di akhirat kelak. Penelitian ini masih memeliki banyak kekurangan, baik itu referensi maupun kolaborasi dengan ahlinya langsung seperti dokter hewan dan lain sebagainya.

\section{Daftar Pustaka}

Abu Muslih Ari Wahyudi. (2014). Gara-gara Menyiksa Seekor Kucing.

Adil Sa'di, A. (2008). Fiqhunnisa Thaharah Sholat.

Baldick, J. (2012). Mystical Islam: an introduction to Sufism. Bloomsbury Publishing.

C.A.I Permatasari. (2016). Etnografi Komunikasi Komunitas Konsumen Penyayang Kucing: Studi pada Komunitas Pecinta Kucing Jakarta. 
Jurnal Riset Agama, Volume 1, Nomor 2 (Agustus 2021): 449-457

M. Faizhil Akbar/Keutamaan Memelihara Kucing dalam Perspektif Islam: Studi

Takhrij dan Syarah Hadits

Universitas Bakrie Jakarta.

Campo, J. E. (2009). Encyclopedia of Islam.

Dalamislam, R. (2021). 15 Pahala Memelihara Kucing yang Istimewa.

Darmalaksana, W. (2020a). Formula Penelitian Pengalaman Kelas Menulis. Jurnal Kelas Menulis UIN Sunan Gunung Djati Bandung. http://digilib.uinsgd.ac.id/32620/

Darmalaksana, W. (2020b). Metode Penelitian Kualitatif Studi Pustaka dan Studi Lapangan. Pre-Print Digital Library UIN Sunan Gunung Djati Bandung.

Ibnu Hajar al-Asqalani. (2010). Fathul Bari Syarah Shahih al-Bukhari, terj. Amiruddin, Fathul Baari Penjelasan Kitab Shahih Bukhari (Jilid 13). Pustaka Azzam.

Khaq, M. (2015). Studi Kritik Kualitas Hadis dalam Kitab al-Nurul al-Burhani $f i$ Tarjamati al-Lujaini al-Dhani Juz II karya KH. Mushlih bin Abdurrahman Mranggen. UIN Walisongo.

Krishandini, K. (2021). Bahan Ajar BIPA Tingkat 6.

Muhammad Nasrullah. (2020). Kisah-kisah dalam Hadis Nabi. Aghitsna Publisher.

Mukhtar, M. (2018). Syarh Hadis dan Fiqh al-Hadis (Upaya Memahami dan Mengamalkan Hadis Nabi). Ash-Shahabah: Jurnal Pendidikan Dan Studi Islam, 4(2), 109-118.

R.M. Siti. (2017). Fenomena Gaya Hidup Komunitas Pecinta Kucing di Bandung. Universitas Pasundan Bandung.

Rizqi Khoirunnisa Nurlayli, D. S. H. (2014). Kesepian Pemilik Hewan Peliharaan yang Tinggal Terpisah dari Keluarga. Jurnal Ilmiah Psikologi Terapan, 2, 1.

Saltanera. (2015). Ensiklopedi Hadits Kitab 9 Imam. Lembaga Ilmu Dan Dakwah Publikasi Sarana Keagamaan, Lidwa Pusaka. https:/ / store.lidwa.com/get/

Srifariyati. (2020). Urgensi Ilmu Jarah Wa Ta'dil dalam Menentukan Kualitas Hadits. Jurnal Madaniyah, 10(1), 131-146. 